\title{
О НЕКОТОРЫХ ПЕРСПЕКТИВАХ РАЗВИТИЯ ЭЛЕКТРОННОГО
ГОСУДАРСТВЕННОГО УПРАВЛЕНИЯ В УСЛОВИЯХ ЦИФРОВОЙ ТРАНСФОРМАЦИИ
}

Статья посвящена анализу базовых направлений развития электронного государственного управления, а также возможностям практической реализации нового принципа “цифровые по умолчанию» в отношении государственных услуг. Отсутствие ожидаемой динамики эффективности обозначенного направления в Российской Федерации актуализирует поднятую тематику. В качестве целей определено предложение авторского определения электронного правительства, а также выявление причин, способствующих торможению реализации платформы электронное правительство и переходу к новому “цифровому» качеству. Методологическую основу составили формально-логический и методы системного и сравнительного правоведения. Выводы по результатам предложены следующие: перспективным является переход от модели электронного к концепции цифрового правительства, основанной на системном преобразовании всей структуры государственного управления. Цифровая стратегия ориентирована на работу с гражданами посредством операций с данными. Под электронным правительством предлагается понимать форму реализации государственного управления, основанную на синергетическом взаимодействии ИКТ и информационных ресурсов (данных) в целях предоставления государственных услуг. Также выделены негативные факторы, тормозящих развитие в нашей стране электронного государственного управления, и обозначены возможные пути их преодоления.

Ключевые слова: электронное правительство; информационные ресурсы; государственное управление; цифровой публичный сервис.

\section{ON SOME PROSPECTS FOR THE DEVELOPMENT OF E-GOVERNMENT IN THE CONDITIONS OF DIGITAL TRANSFORMATION}

The article is devoted to the analysis of basic directions of the development of e-government, as well as the possibilities for the practical implementation of the new principle of "digital defaults" in the provision of public services. However, the absence of the expected dynamics of the effectiveness of e-government in the Russian Federation actualizes the topic raised. The article studies a reasonable development, e-government and the transition to a new "digital" quality, as well as the proposal of the author's definition of "e-government". The methodological basis of the article is formal-logical processes and methods of systemic and comparative law. The conclusions on the results suggested the following: a promising transition from the "e-gov-

Парадигмы нового информационного мира диктуют свои требования к механизму государственного управления. Информационно-коммуникационные технологии (далее ИКТ) в современной России также стали частью управленческих систем во всех отраслях и ссрерах государственного управления, обеспечения безопасности и правопорядка. В настоящее время государственное управление общепризнанно рассматривается как системный процесс, элементы которого объединены с помощью ИКТ.

Использование ИКТ в государственном управлении связано с развитием инновации «электронное правительство» [17, с. 21-22], начавшейся ernment" model to the concepts of government based on the systemic transformation of the entire government structure. The digital strategy is focused on working with citizens through data operations. It is proposed to understand e-government as a form of implementation of public administration, based on the synergetic interaction of ICT and information resources (data) for the provision of public services. Also, negative factors hindering the development of e-government in our country are highlighted, and possible ways to overcome them are outlined.

Key words: e-government; information resources; governance; digital public service.

для нашего государства в 2000 г. с принятия Окинавской Хартии глобального информационного общества [11]. Как отмечается в научной литературе, осуществление этих инноваций на основе имплементации ИКТ в сфере государственного управления расширяет возможности оборота информационных ресурсов в правотворческой и правореализующей деятельности на разных уровнях [16, с. 66].

Нормативно электронное правительство было закреплено в Концепции формирования в Российской Федерации электронного правительства до 2010 г., утв. распоряжением Правительства РФ от 6 мая 2008 года №632-р [7], как новая форма 
организации деятельности органов публичной власти, обеспечивающая за счет широкого применения ИКТ качественно новый уровень оперативности и удобства получения организациями и гражданами публичных услуг и информации о результатах деятельности публичных органов.

По фракту выделялись две стратегические линии новой организации государственного управления: во-первых, формирование единых информационных систем для обеспечения доступа граждан и организаций к результатам деятельности органов публичной власти; во-вторых, предоставление публичных услуг с использованием ИКТ [5, с. 72]. Указанные направления реализовались на основе федеральных программ развития «Электронная Россия» и «Информационное общество».

Как отмечает Н. Н. Ковалева, электронное правительство это концепция осуществления государственного управления, основанная на возможностях ИКТ и ценностях открытого гражданского общества [6, с. 82]. По мнению Бачило И. Л., электронное правительство представляет собой совокупность (систему) органов и организаций, непосредственно ориентированных на формирование условий в целях формирования информационного общества, создание таких параметров российского государства, при которых это государство и будет рассматриваться как информационное общество [2, с. 275-275].

Но с точки зрения пользователя, как нам видится, - электронное правительство это форма реализации государственного управления, основанная на синергетическом взаимодействии ИКТ и информационных ресурсов (данных) в целях предоставления государственных услуг.

Следует отметить, что при реализации электронного правительства различают технологическую и коммуникативную компоненты. Технологическая компонента в управлении связана с процессами информатизации, с упором на применение ИКТ в управлении как вспомогательного инструментария. Коммуникативная компонента выражается в активном внедрении ИКТ в государственное управление в целях создания прозрачной информационной среды, повышения открытости публичной власти, более эфффективного взаимодействия власти и населения, становления и упрочения электронной демократии в России $[18$, с. 113]. В указанной Концепции присутствовали обе компоненты, однако на первых этапах акцентировался именно технологический подход в организации электронного правительства, как способ модернизации существующих государственных управленческих структур и услуг с помощью ИКТ [4, с. 109].

К сегодняшнему дню для развития электронного государственного управления принят комплекс федеральных законов, на основе которых создан портал публичных услуг, обеспечивается прозрачность деятельности органов публичной власти, активно развивается межведомственное взаимодействие, основанное на принципе «одного окна». Кроме того, основные перспек- тивные направления отражены в Стратегии развития информационного общества в Российской Федерации на 2017-2030 гг., утвержденной Указом Президента РФ от 09 мая 2017 №203 (далее Стратегия развития информационного общества в РФ) [19].

Обращаем внимание, что в ходе оценки $\mathrm{O}$ 2018 г. рейтинг России по уровню развития электронного правительства составил 32 место, что несколько улучшило наш показатель 2016 г. [15] Однако наращивание уровня информатизации и количества электронных государственных услуг в настоящий момент являются недостаточными фракторами не только для развития, но и для перехода на новый уровень электронного (цифрового) управления. Тем не менее, в указанной Стратегии развития информационного общества сохраняются отдельные элементы технологического подхода, определяя роль ИКТ зачастую как обеспечительную, вспомогательную для государственного управления.

Также в научной литературе подчеркивается, что электронное правительство России, структурно дезинтегрированное, реализующее ведомственный подход к оказанию публичных услуг, сосредоточенное на управлении сервисами, децентрализованное, с рядом дублирующих функций, имеющее отдельные узкоспециализированные узлы, еще далеко от правительства, организованного по сетевому принципу, использующего свой потенциал для совместной с обществом и бизнесом выработки решений проблем стратегического и экономического развития [12, c. 27]. Эта точка зрения подтверждается практическими материалами, в частности, в Государственной программе РФ «Информационное общество (2011-2020г.)” акцентируется внимание на комплексе проблем государственного управления в условиях использования ИКТ: низкие темпы развития инновационной экономики ведут к недостаточному присутствию на рынке отечественных ИКТ, к зависимости от иностранных информационных технологий, низкой конкурентоспособности российских IT-компаний и отечественной электронной базы; высокий уровень «информационного неравенства» в различных субъектах Федерации и различными слоями населения; рост угроз информационной безопасности, в том числе, кибератак на государственные информационные системы, что может вызывать недоверие к эффективности защиты данных граждан в таких системах и др. [13].

Лидеры же электронного правительства (Дания, Великобритания и др.), преодолевая негативные факторы, в настоящий момент уже переходят от электронного правительства - к цифровому, что подразумевает перевод государственных услуг в цифровой формат от момента обращения за услугой до их исполнения, опираясь преимущественно на данные, а не на документы.

Иными словами, все управленческие процессы трансформируются на основе принципа «цифровые по умолчанию». Так, например, стратегия «хороших базовых данных» [24] правительства 
Дании оценивает неоднократное использование данных как первооснову для эфффективного выполнения органами государственной власти своих задач, а также как существенный вклад в модернизацию государственного сектора. Это выражается не только в обеспечении высокого качественного обслуживания граждан и организаций при совместном использовании ведомствами ранее введенных данных в процессе рассмотрения обращений, но и освобождает государственных служащих от повторяющихся рутинных операций и процедур. С 2004 г. Дания активно инвестирует в цифровизацию государственных органов. С 2015 г. взаимодействие граждан и бизнеса с государственными структурами производится только через Интернет. Органы власти на уровне страны и муниципалитетов связаны в единую сеть, что позволяет взаимодействовать со всеми ведомствами с помощью единого личного кабинета [23]. Как отмечается самими датчанами, если вам нужно заплатить налоги, сообщить о краже велосипеда или записаться на прием в службу общественного здравоохранения в Дании, вы можете сделать все это со своего компьютера. Каждый орган государственной власти или государственное должностное лицо может быть доступно онлайн, и каждый гражданин имеет определенную цифровую подпись для «подписания» важных документов [22].

Другим лидером в сорере реализации электронного правительства является Великобритания, представившая в 2017 г. новую стратегию развития цифрровых технологий (Digital Strategy) по семи направлениям развития «ведущей цифровой экономики» в мире, где одним из направлений выделяется «цифровое правительство». Согласно Стратегии транссоомации правительства до 2020 г. [25] следующий этап цифровой трансформации “цифрового правительства" (здесь и далее под трансформацией понимается - «преобразование» государственного управления и предоставления публичных услуг) состоит из $3-x$ компонентов, которые в совокупности формируют рамки этой стратегии:

1) трансформация цифрровых услуг в государственном секторе, ориентированных на всех пользователей и везде, где это возможно;

2) полная трансформация департамента, путем преобразования способов предоставления своих услуг, с помощью цифровых технологий, что приведет к более гибкому управлению, улучшит обслуживание граждан по всем каналам и повысит эфффективность;

3) внутренняя трансформация правительства, которая не обязательно внешне повлияет на публичные сервисы, но имеет значение для повышения уровня межведомственного взаимодействия, путем преобразования внутреннего управления [14]

В Стратегии трансформации правительства Великобритании, выделяются 5 основных целей ее реализации (достижения):

1) предоставление цифровых услуг мирового класса и преобразование методов работы прави- тельства, от переднего плана до бэк-офиса, современным и эфффективным способом;

2) развитие высоких навыков пользования ИКТ и повышение интернет-культуры в гражданском обществе и бизнесе;

3) создание новых цифровых инструментов и упрощение процедур в государственном секторе, повышение эфрфективности работы государственных служащих;

4) более эффективное использование данных не только для обеспечения прозрачности, но и для обеспечения трансформации государственного и частного сектора;

5) создание, эксплуатация, итерация и внедрение эфффективных общих платформ (основ) цифрового правительства и использование многоразовых бизнес-возможностей для ускорения трансформации, основываясь на общих открытых стандартах, шаблонах [26].

Иными словами, цифровое правительство ориентировано на нужды и ожидания граждан (общества); публичные цифрровые услуги оперативнее и дешевле; совершенствование публичных цифровых услуг происходит на основе информационных ресурсов (данных), как имеющихся в наличии, так и вновь создаваемых в ходе государственного управления. Так, Эстонии удалось выстроить эффективную электронную систему государственного управления благодаря принятию в 1997 г. правилу, не позволяющему государственным служащим требовать от граждан информационный ресурс (данные), уже однажды полученную в любом другом государственном учреждении. У большинства граждан есть электронный паспорт - ID Card, который позволяет получать публичные услуги онлайн, в том числе голосовать на муниципальных и парламентских выборах. В 2005 г. Эстония первой ввела электронное голосование; в 2015 г. в ходе выборов в парламент более 30 \% избирателей голосовали онлайн. Электронная цифровая подпись в стране законодательно приравнена к обычной, и активно используется с 2002 г. [23].

Как заявлено в аналитическом докладе «Цифрровое правительство 2020: Перспективы для России", подготовленного Всемирным банком совместно с Институтом развития информационного общества, цифровой административный процесс дает ряд преимуществ по эффективности управления. Он позволяет не только отслеживать движение заявлений, в том числе, обеспечивая постоянное информирование заявителей услуг о прохождении этапов. Но и, путем предоставления данных по обработке транзакций, обеспечивает возможность применения ИКТ, основанных на использовании данных. Это может включать автоматизированную проверку заявлений не только по существующей базе данных услуги, но также и по межведомственным базам данных; идентификацию обращений и направление их на рассмотрение соответствующим специалистам; постоянный пересмотр регламентных правил рассмотрения обращений с ориентацией на данные для обеспечения максимальной эффективности использо- 
вания имеющихся ресурсов. Причем полагается, что принцип «цифровой по умолчанию» может изменить и суть самой государственной услуги, делая ее также цифровой (например, электронные визы, введенные рядом стран) [1].

Однако в России системной переоценки цифровой организации еще не произошло, что сдерживает развитие нового этапа электронного государственного управления, в том числе, по ряду географических, демографических, экономических причин. Так, в качестве альтернативы сохраняются традиционные способы (неэлектронные) оказания публичных услуг, так как часть населения страны нуждается не только в повышении компьютерной грамотности, но и в выравнивании возможностей доступа к этим электронным услугам. Решить эту задачу без государственной социальной поддержки не представляется возможным. Также важнейшим условием развития данного направления является организация систематического повышения квалификации служащих публичных органов по работе с ИКТ и в сфере информационной культуры. Однако присутствие «альтернативы» не мотивирует и само государство на изменение концептуального подхода в оказании публичных услуг. Более того, сохранение традиционного, «привычного» варианта получения публичной услуги закреплено в качестве принципа в Стратегии развития информационного общества в РФ. Иными словами, признается, что часть российского общества не готова к преобразованиям, не может оценить преимущества использования в своей жизни, профессиональной и иной деятельности ИКТ. Однако, на наш взгляд, основным условием реализации и дальнейшего развития электронного правительства выступает именно способность (возможность) граждан быть участниками электронного государственного управления и именно это положение как базис (принцип) должно браться за основу дальнейшего реформирования. Здесь можно обратиться к положительному опыту ряда зарубежных стран, предоставляющим в помощь своим гражданам, с недостаточными цифровыми навыками, бесплатное обучение детям и взрослым, в том числе, государственным служащим, включив работу с ИКТ в состав общего образования и создав, таким образом, информационную среду, готовую к цифровой трансформации. Например, в Сингапуре также организована помощь нуждающимся в подключении к цифровым сервисам, для этих целей созданы центры подключения граждан, в которых сотрудники помогают населению получить доступ к государственным услугам. А вот получение документа в очной форме, через взаимодействие с чиновником на личном приеме, является отдельно оплачиваемой услугой [8]. Этот опыт можно использовать в целях преобразования работы многофункциональных центров из посредников по оказанию государственных услуг в центры помощи подключения к цифровым сервисам

Кроме того, ряд норм действующего законодательства РФ являются «тормозом» развития цифрового управления, ориентируясь преиму- щественно на традиционные механизмы государственного управления. Так, в соответствии с законодательством РФ об обращениях граждан, общий срок порядка рассмотрения обращений составляет 30 дней [20], исключая возможность мгновенного исполнения при электронном обращении, что не оправдывает ожидания электронного документооборота. Очевидно, что темпы социальных изменений в ходе технического прогресса ускоряются и это повышает ожидания людей в отношении того, что государственное управление будет применять современные методы и технологии для улучшения своих услуг и межведомственного взаимодействия. Традиционное право не успевает за этими трансоормациями, что также требует преобразования правовой платформы государственного управления.

Иными словами, необходимо реформирование законодательства, в том числе, административных регламентов, на основе которых осуществляются административные процедуры. Именно законодательство априори является организационным и интегрирующим фактором в отношении инфраструктуры электронного правительства, стимулом для практического развития этого направления

В качестве инфраструктуры электронного правительства в Стратегии развития информационного общества в РФ рассматривается совокупность размещенных на территории страны государственных информационных систем программно-аппаратных средств и сетей связи, с помощью которых обеспечивается при оказании услуг и осуществлении иных функций в электронной форме межведомственное взаимодействие органов публичной власти, граждан и организаций. На наш взгляд, необходимо данное определение дополнить элементом - информационные ресурсы (данные), без которых представляется невозможным не только оказание публичных услуг, но собственно ради которых большинство услуг востребованы (в виде результата этой услуги).

Ресурсы (из франц. ressource «вспомогательное средство») определяются как источники чего-либо [10, с. 885]. Информация (из лат. informatioизложение, разьяснение) сообщения (данные), осведомляющие о положении дел [10, с. 232]. В ст. 2 Федерального закона от 27 июля 2006 г. № 149-ФЗ «Об информации, информационных технологиях и о защите информации» информация это сведения, сообщения (данные), независимо от формы их представления [21].

В юридической науке нет однозначного подхода к вопросу о том, какую информацию следует считать ресурсом, а какая информация таковым не является. В действующем законодательстве, не смотря на широкое применение термина, легальная дефиниция информационного ресурса отсутствует, что является несомненным пробелом, исходя из стратегической значимости для электронного государственного управления данной категории.

В науке существуют различные трактовки этого определения. Наиболее распространенной 
точкой зрения является положение о том, что информационные ресурсы это отдельные документы и отдельные массивы документов, документы и массивы документов в информационных системах. Иными словами, исходным моментом включения информации в сферу обращения по различным социальным каналам является ее документирование, то есть закрепление на материальном носителе. Однако, по мнению некоторых авторов, сужение «информационного ресурса» лишь к документированной информации необоснованно, так как «очевидно, что в Интернете абсолютное большинство циркулирующей информации никак нельзя отнести к традиционному документообороту» [3, с. 121-130]. К информационным ресурсам относят не только совокупность информации и материального носителя (документ), но и собственно сведения, то есть выделяется содержательная (идеальная) сторона информации [9, с. 81-89].

Можно определить следующие признаки информационного ресурса: это документ или структурированный массив документов (система документов); имеет определенную фоорму, удобную для формирования, хранения, передачи и восприятия; содержит социально значимую информацию, отобранную по определенным признакам.

Анализируя сказанное, можно сделать вывод о том, что при разработке дефиниции «инорормационный ресурс», законодателю следует учитывать не только его материальную, но и идеальную (содержательную) сторону.
Нам же представляется, что информационный ресурс это сведения (социально значимая информация), сформированные по определенному критерию (признаку) и зафиксированные на материальном носителе в любой форме представления.

Таким образом, информация (оцифрованные данные) становится стратегическим ресурсом государственного управления. Однако эффективный переход на цифровую платформу государственного управления возможен при системном подходе по всем направлениям цифрового правительства, в том числе, внесение изменений в законодательство, в административные внутриведомственные процессы, повышение компьютерной грамотности и информационной культуры государственных служащих и населения, технологической инфраструктуры и инвестиционных моделей и др.. Проведенное сравнительное исследование зарубежного опыта стран-лидеров по реализации перехода от модели «электронного правительства» к «цифровому правительству" представляется крайне актуальным для их возможного практического воплощения при преобразовании российского государственного управления. В частности, это дает понимание того, что в обозримом будущем наибольшая доля публичных услуг будет предоставляться в цисрровом формате и необходима государственная поддержка тем, кто не может получить доступ к цифровым сервисам.

Литература

1. Аналитический доклад «Цифровое правительство 2020: Перспективы для России», подготовленного Всемирным банком совместно с Институтом развития информационного общества. URL: http://www.iis.ru/docs/ DigitalGovernmentRussia2020RUS.pdf (Дата обращения: 19.10.2018).

2. Бачило И. Л. Правовая платформа построения электронного государства. Конфликты в информационной сфере: правовые аспекты. Материалы теоретич. семинара Сектора информационного права института государства и права РАН. М.: Институт государства и права РАН, 2009. С. 271-283.

3. Войниканис Е. А., Якушев М. В. Информация. Собственность. Интернет: Традиция и новеллы в современном праве. М.: Волтерс Клувер, 2004. 176 с

4. Иншакова Е. Г. Стадии развития «электронного правительства» // Правовая наука и реформа юридического образования. 2012. № 2(25). С. 109-113.

5. Ковалева Н. Н. Государственное управление в информационной сфере: монография. Саратов: КУБиК, 2011. 224 с.

6. Ковалева Н. Н. Информационное право России: учебное пособиею. М.: «Дашков и К», 2007. 360 с.

7. Концепция формирования в Российской Федерации электронного правительства до 2010 года, утв. распоряжением Правительства РФ от 6 мая 2008 года №632-р // Собрание законодательства Российской Федерации. 2008. №20 Ст. 2372.

8. Москва будет использовать опыт Сингапура в цифровизации госуслуг URL: https://tass.ru/ekonomika/5382233 (Дата обращения: 03.11.2018).

9. Огородов Д. В. К вопросу о правовой охране информации // Интеллектуальная собственность: современные правовые проблемы: Проблемно-тематический сб. М.: ИГП, ИНИОН РАН, 1999. С. 81-89.

10. Ожегов С. И. Словарь русского языка / Под общ. ред. проф. Л. И. Скворцова. М.: ООО «Издательство Оникс» ООО «Издательство «Мир и образование», 2007. 1200 с.

11. Окинавская хартия глобального информационного общества // Дипломатический вестник. 2000. №8. С. 51-56.

12. Павлютенкова М. Ю. Электронное правительство России в новых условиях // PolitBook. 2015. №2. C. 6-32.

13. Постановление Правительства РФ от 15.04.2014 N 313 (ред. от 25.09.2018) «Об утверждении государственной программы Российской Федерации «Информационное общество (2011-2020 годы) // Собрание законодательства Российской Федерации. 2014. №18 (часть II). Ст. 2159.

14. Правительство Британии становится на путь цифровой трансформации. URL: http://d-russia.ru/pravitelstvobritanii-stanovitsya-na-put-tsifrovoj-transformatsii.html (Дата обращения: 05.11.2018).

15. Рейтинг электронного правительства OOH. URL: http://www.tadviser.ru/index.php/ (Дата обращения: 10.09.2018) 
16. Силков С. В. Электронное правительство в Беларуси: правовое регулирование конфронтаций в информационной сфере. Конфликты в информационной сфере: правовые аспекты. Материалы теоретич. семинара Сектора информационного права института государства и права РАН. М.: Институт государства и права РАН, 2009. С. 64-81.

17. Талапина Э. В. Государственное управление в информационном обществе (правовой аспект): монография. М.: Юриспруденция, 2015. 192 с.

18. Холопов В. А. Правовые аспекты совершенствования институтов непосредственной демократии и информационного обеспечения местного самоуправления // Вопросы государственного и муниципального управления. 2011 №4. C. $106-115$.

19. Указ Президента РФ от 09.05.2017 N 203 «О Стратегии развития информационного общества в Российской Федерации на 2017-2030 годы» // Собрание законодательства Росийской Федерации. 2017. №20. Ст. 2901.

20. Федеральный закон от 02.05.2006 N 59-Ф3 (ред. от 27.11.2017) «О порядке рассмотрения обращений граждан Российской Федерации»// Собрание законодательства Росийской Федерации. 2006. №19. Ст. 2060.

21. Федеральный закон от 27 июля 2006 г. N 149-Ф3 (ред. от 19.07. 2018 г. ) «Об информации, информационных технологиях и о защите информациил // Собрание законодательства Росийской Федерации. 2006. №31 (часть I). Ст. 3448.

22. Цифровизация в Дании. URL: https://denmark.dk/innovation-and-design/digitalisation (Дата обращения: 10.09.2018).

23. Четыре электронных лидера. URL: http://www.rbcplus.ru/news/5acf36437a8aa92bcba1 ef50?ruid=NaN (Дата oбpaщения: 05.11.2018)

24. The Danish Government 2012. URL: http://www.fm.dk/publications/2012/good-basic-data-for-everyone/ /media/ Publikationer/Imported/2012/Gode\%20grunddata\%20til\%20alle/BasicData_UK_web_2012.10.08. (Дата обращения: 20.10.2018)

25. GOV.UK: официальный портал правительства Великобритании. URL: https://www.gov.uk/government/publications/ uk-digital-strategy/uk-digital-strategy\#contents (Дата обращения: 05.11.2018).

26. Government Transformation Strategy 2017 to 2020 . URL: https://www.gov.uk/government/publications/governmenttransformation-strategy-2017-to-2020/government-transformation-strategy (Дата обращения: 05.11.2018)

\section{References}

1. Analiticheskiy doklad «Tsifrvoye pravitel'stvo 2020. Perspektivi dlya Rossii», podgotovlennogo Vsemirnim bankom sovmestno s Institutom razvitiya informacionnogo obshestva (The Analytical Report "Digital Government 2020: Perspectives for Russia", Prepared by the World Bank in Conjunction with the Institute of the Information Society) URL: http://www.iis.ru/ docs/DigitalGovernmentRussia2020RUS.pdf (Accessed: 10.19.2018). (In Russian).

2. Bachilo I. L. Pravovaya platforma postroeniya elekronnogo gosudarstva. Konflikti $v$ informacionnoy sfere: pravovie aspekti (Legal Platform for Building an Electronic State. Conflicts in the Information Sphere: Legal Aspects). Materiali teoretich. seminara Sektora informacionnogo prava instituta gosudarstva i prava RAN. Moscow: Institute of state and law of RAS publ. 2009. P. 271-283. (In Russian).

3. Voynikanis E. A., Yakushev M. V. Informacia. Sobstvennost'. Internet: Tradicia i novelli v sovremennom prave (Information. Own. Internet: Tradition and New Things in Modern Law). Moscow: Volters-Kluver, 2004. 176 p. (In Russian)

4. Inshakova E. G. Stadii raswitiya (elektronnogo pravitelstva» (Stages of Development of "E-Government") // Pravovaya nauka i revorma yuridicheskogo obrasovaniya. 2012. No.2 (25). P. 109-113. (In Russian).

5. Kovaleva N. N. Gosudarstvennoe upravlenie v informacionnoy sfere: monografia. (Public Administration in the Information Sphere: Monograph). Saratov: KUBiK, 2011. 224 p. (In Russian).

6. Kovaleva N. N. Informacionnoe pravo Rossii: uchebnoe posobie (Information Law of Russia: Textbook). Moscow Dashkov and K, 2007. 360 p. (In Russian).

7. Koncepciya formirovaniya $v$ Rossiiskoi Federatsii electronnogo pravitelstva do 2010 goda, utv. rasporyazheniem Pravitelstva RF of 6 maya 2008 goda №632-r. (The Concept of Forming E-Government in the Russian Federation until 2010, Approved. Order of the Government of the Russian Federation of May 6, 2008 No. 632-p) // Sbornik zakonodatel'stva Rossiiskoi Federatsii. 2008. No. 20. Art. 2372. (In Russian).

8. Moscva budet ispol'sovat' opit Singapura v tsifrovisacii gosuslug (Moscow Will Use the Experience of Singapore in the Digitization of Public Services) URL: https://tass.ru/ekonomika/5382233 (Accessed: 03.11.2018). (In Russian).

9. Ogorodov D. V. K voprosu o pravovoy ohrane informatsii (On the Issue of Environmental Protection) // Intellectual'naya sobstvennost': sovremenniye pravovie problemi. Problemno-tematicheskiy sb. / Moscow: IGP, INION RAN, 1999. P. 81-89 (Accessed: 03.11.2018). (In Russian)

10. Ozhegov S. I. Slovar' russkogo yasika. (Dictionary of the Russian language). Pod obsh. red. prof. L. I. Skvorcova. Moscow: 000 «Isdatel'stvo Onix»: OOO «Isdatel'stvo «Mir i obrasovanie», 2007. 1200 p. (In Russian).

11. Okinawskaya Khartiya global'nogo informatsionnogo obshchestwa (Okinawa Charter of the Global Information Society)// Diplomaticheskaya Gazeta. 2000. No. 8. P.51 - 56. (In Russian).

12. Pavlyutenkova M. Yu. Electronnoye pravitel'stvo Rossii v novih usloviyah. (E-government of Russia in the New Conditions) // PolitBook. 2015. No. 2. P.6 - 32. (In Russian)

13. Resolution of the Government of the Russian Federation of April 15, 2014 N 313 (as amended on September 25 2017) "Ob utverzhdenii gosudarstvennoy programmi Rossiiskoy Federatsii "Informacionnoe obshchestvo" (2011-2020) (On Establishing the State Program of the Russian Federation "Information Society" (2011-2020) // Sbornik zakonodatel'stva Rossiiskoi Federatsii. 2014. No. 18 (Part II), Art. 2159. (In Russian)

14. Pravitel'stvo Britanii stanovitsya na put' tsifrovoy transformatsii (The British Government Takes the Path of Digital Transformation) URL: http://d-russia.ru/pravitelstvo-britanii-stanovitsya-na-put-tsifrovoj-transformatsii.html (Accessed: 05/11/2018). (In Russian).

15. Rating of UN Electronic Government. URL: http://www.tadviser.ru/index.php/ (Accessed: 10.09.2018). (In Russian) 
16. Silkov S. V. Electronnoye pravitel'stvo $v$ Belarussi: pravovoe regulirivanie konfrontatsiy $v$ informatsionnoy sfere (E-government in Belarus: Legal Regulation of Confrontations in the Information Sphere) // Konflikti v informatsionnoy sfere: pravovie aspekti. Materiali teoretich. seminara Sektora informacionnogo prava instituta gosudarstva i prava RAN. Moscow: Institute State and Law of RAS, 2009. P. 64-81. (In Russian).

17. Talapina E. V. Gosudarstvennoe upravlenie v informatsionnom obshchestve (pravovoy aspect): monografiya. (Public Administration in the Information Society (Legal Aspect): Monograph). Moscow: Yurisprudenciya, 2015. 192 p. (In Russian).

18. Kholopov V. A. Pravovie aspekti sovershenstvovaniya institutov neposredstvennoy demokratii i informatsionnogo obespecheniya mestnogo samoupravlenaya (Legal Aspects of the Development of State and Municipal Government) // Voprosi gosudarstvennogo i municipalnogo upravleniya. 2011. No.4. P. 106-115. (In Russian).

19. Presidential Decree of 09.05.2017 N 203 "O strategii rasvitiya informacionnogo obshchestva v Rossiiskoi Federatsii na 2017-2030" ("On Strategies for the Development of the Information Society in the Russian Federation for 2017-2030") /I Sbornik zakonodatel'stva Rossiiskoi Federatsii. 2017. No.20. Art. 2901. (In Russian).

20. Federal Law of $02.05 .2006 \mathrm{~N} 59-\mathrm{FZ}$ (as amended on 27.11.2017) "O poryadke rassmotreniya obrashcheniy grazhdan Rossiiskoi Federatsii" ("On the Procedure for Considering Applications from Citizens of the Russian Federation") // Sbornik zakonodatel'stva Rossiiskoi Federatsii. 2006. No. 19. Art. 2060. (In Russian).

21. Federal Law of July 27,2006 N 149-FZ (as amended on July 19, 2018) "Ob informatsii, informatsionnih tehnologiah i o zashchite informatsii" ("On Information, Information Technologies and on Protection of Information") // Sbornik zakonodatel'stva Rossiiskoi Federatsii. 2006. No. 31 (Part I). Art. 3448. (In Russian).

22. Digitization in Denmark. URL: https://denmark.dk/innovation-and-design/digitalisation

23. Electronic leaders. URL: http://www.rbcplus.ru/news/5acf36437a8aa92bcba1 ef50?ruid=NaN (Accessed: 05.11.2018) (In Russian).

24. Danish Government 2012. URL: http://www.fm.dk/publications/2012/good-basic-data-for-everyone/ /media/ Publikationer/Imported/2012/Gode\%20grunddata\%20til\%20alle/ BasicData_UK_web_2012 .10.08. (Accessed: 20.10.2018). (In Russian)

25. GOV.UK: the official portal of the UK government. URL: https://www.gov.uk/government/publications/uk-digital-strategy/ uk-digital-strategy\#contents (Accessed: 05.11.2018). (In Russian).

26. Government Transformation Strategy 2017 to 2020. URL: https://www.gov.uk/government/publications/governmenttransformation-strategy-2017-to-2020/government-transformation-strategy (Accessed: 05.11.2018). (In Russian). 